Espaço Aberto | Open Space

http://dx.doi.org/10.1590/S0104-71832020000300013

\title{
Evangélicos à direita
}

\section{Evangelicals on the right wing}

\author{
Ronaldo de Almeida* \\ *Universidade Estadual de Campinas - Campinas, SP, Brasil \\ ronaldormalmeida@gmail.com \\ https://orcid.org/0000-0003-0068-2585
}




\title{
Resumo
}

É bastante consensual no debate público nacional e internacional que está em curso uma onda conservadora no interior da qual algumas religiões são protagonistas. Dentre elas, destacam-se parte significativa dos evangélicos, mas não a sua totalidade. Este artigo pretende discutir sobre os evangélicos posicionados à direita do espectro político brasileiro. Parto da constatação de que o início da crescente atuação de setores evangélicos na política institucional ocorreu nos anos 1980, contudo, aquilo que hoje é classificado como conservador e "de direita" antecedem a presença pública desses religiosos. Assim, três décadas depois, qual a especificidade do conservadorismo evangélico? O que ele aporta de novo às estruturas mais longevas da sociedade brasileira? Minha hipótese mais geral é que esses evangélicos acentuam no discurso e nas práticas a separação, a concorrência e o conflito religiosos, e na conjuntural atual confundem, intencionalmente, ocupação do governo federal com ter maioria demográfica para legitimar normas morais conservadoras.

Palavras-chave: evangélicos; conservadorismo; Bolsonaro; direita política.

\begin{abstract}
There is a consensus both nationally and internationally that we are witnessing a conservative wave in which some religions are protagonists. These include many, but not all, evangelicals. This article aims to discuss the evangelicals on the right wing of the Brazilian political spectrum. The increasing presence of evangelical sectors in institutional politics dates back to the 1980s. However, those sectors that are considered conservative or "right wing" predate the public presence of evangelicals. This raises the question, after more than three decades, as to what evangelical conservatism is. What does it add to the historical, deeply rooted conservative structures in Brazilian society. My general hypothesis is that these evangelicals deepen religious division, competition and conflicts in their discourses and practices. And in the current conjuncture, they intentionally confuse being in government with having a demographic majority to legitimize conservative moral standards.
\end{abstract}

Keywords: Evangelicals; conservatism; Bolsonaro; right wing. 
A Flávio Pierucci.

\section{Ontem e hoje}

Começo essa reflexão citando o parágrafo inicial do artigo do sociólogo da religião, Flávio Pierucci (1987, p. 26, grifo do autor), no qual define pessoas da cidade de São Paulo identificadas politicamente como "de direita":

Seu tique mais evidente é sentirem-se ameaçados pelos outros [...] Eles têm medo. Abandonados e desorientados em meio a uma crise complexa, geral, persistente, que além de econômica e política é cultural, eles se crispam sobre o que resta de sua identidade moral em perdição, e tudo se passa como se tivessem decidido jogar todos os trunfos na autodefesa. "Legítima defesa" poderia muito bem ser um termo-chave do seu vocabulário. A autodefesa, que é prima facie a proteção de suas vidas, de seus casas e bens, da vida e da honra de seus filhos (suas filhas!), sua família, é também a defesa dos seus valores enquanto defesa de si diante da inversão dos valores em curso. (Mas isto é ser de direita?).

Embora ressoe atualíssima, a citação encontra-se em um artigo de mais de três décadas publicado na revista Novos Estudos. Mais precisamente, a publicação ocorreu em 1987, entre a eleição para a Assembleia Constituinte, em 1986, e a promulgação da nova Constituição do Brasil, em 1988. Com um título que é, de imediato, intrigante para os dias atuais - "As bases de uma nova direita" -, o artigo transpira os ares da redemocratização após duas décadas de regime militar. Mas no sentido oposto à literatura predominante da época que estava mais preocupada com os agentes, as práticas e os discursos da recém-reconquistada democracia, Pierucci analisou em torno de 150 entrevistas com eleitores de Jânio Quadros e Paulo Maluf, vetores sociais reativos àquele novo quadro político. Como afirmou posteriormente no livro Ciladas da diferença (Pierucci, 2013), a pesquisa foi motivada pela vitória de Jânio para a prefeitura de São Paulo, em 1985, quando derrotou Fernando Henrique Cardoso em sua primeira eleição. O objetivo foi circunscrever uma constelação (termo do autor) de ideias e valores políticos de direita no contexto pós-ditadura nos bairros tradicionais das zonas Leste e Norte, onde Jânio foi mais votado: 
predominantemente católico, de menor presença nordestina em relação a outras regiões da cidade, de classes média e média baixa e com pouca e média escolaridades.

Um dos efeitos do artigo de Pierucci é a constatação de que os temas controversos de hoje e de meados dos anos 1980 demonstram muitas continuidades e alguns deslocamentos sofridos pela sociedade brasileira. Com a finalidade de refletir sobre a conjuntura atual, tomo sua análise como referente de uma constelação de elementos agrupados naquele momento como a "nova direita". Não se trata propriamente de traçar paralelos entre os momentos políticos (o início da redemocratização em meados dos anos 1980 e o momento atual de crise global da democracia liberal), mas compreender alguns deslocamentos e continuidades da sociedade brasileira.

Começo pela diferença principal. O que se deslocou de mais englobante foi a configuração das legitimidades políticas. No contexto da Constituinte, direita era "um nome que não se diz" (Pierucci, 1987, p. 36). Expressão disso foi o famoso "voto envergonhado" em Jânio Quadros, em 1985, que lhe garantiu uma inesperada vitória para a prefeitura de São Paulo. Hoje, todavia, esquerda é o nome que não se diz, pois foi criminalizada pela prática da corrupção. A bandeira da ética das esquerdas, construída na resistência ao regime militar e no início da redemocratização, foi sendo desconstruída conforme assumiram cargos dos poderes Executivo e Legislativo.

O caso Mensalão, no final do primeiro governo Lula, em 2005, deixou entre outros legados a indistinção ética entre partidos do espectro político, de tal modo que as fronteiras entre os três maiores (PT, PSDB e PMDB) foram ficando cada vez menos evidentes em algumas práticas. A Operação Lava Jato, iniciada em abril de 2014, e o caso Petrolão, no final do primeiro mandato de Dilma Rousseff, deram "uma volta a mais no parafuso" e criminalizaram de forma contundente o campo político à esquerda, em particular o seu maior partido e ator político: o PT e o ex-presidente Lula. A derrota avassaladora das esquerdas nas eleições municipais de 2016 (quando o maior vencedor foi o PSDB) somada às vitórias, em 2018, de candidaturas de direita e de extrema direita nos poderes Executivo e Legislativo (federal e estadual) indicaram que as legitimidades haviam se deslocado ainda mais. Nas narrativas dos que estão vencendo o atual processo político, as esquerdas são consideradas estruturalmente corruptas e o campo político à direita é composto por 
"pessoas de bem", principalmente por aqueles que não fazem parte do corruptor sistema político. ${ }^{1}$

Se em relação ao cenário da Constituinte a legitimidade ética foi deslocada da esquerda para a direita, existem, em contrapartida, algumas continuidades com a conjuntura atual. $\mathrm{O}$ discurso da meritocracia e do empreendedorismo, por exemplo, já estava na constelação daquela direita dos anos 1980. Mas, lá como hoje, não havia uma sustentação rigorosa do discurso neoliberal em defesa do Estado mínimo entre as camadas populares e média baixa. Sua principal crítica ao Estado está em sua corrupção endêmica e nos privilégios de parte do funcionalismo público. Entretanto, essa indisposição das classes médias e populares foi capturada pelo discurso pró-Estado mínimo, que, em termos concretos, é orientado pela perspectiva neoliberal de redução da proteção social. Em outras palavras, o discurso favorável ao "Estado mínimo" tem sentidos distintos entre os estratos sociais, que foram alinhados na eleição de Bolsonaro em torno do empreendedorismo individual e do combate à corrupção do sistema político.

O discurso econômico neoliberal tem pouco apelo eleitoral. Não por acaso ele está em conexão com duas outras dimensões da vida social brasileira com grande apelo: a segurança e os costumes. Tanto em Pierucci como no contexto atual o tema da segurança tem sido bandeira política das direitas, enquanto as esquerdas (com algumas exceções) têm dificuldade em formular um discurso político de combate à criminalidade que destaque e legitime o emprego da força policial, e que vá além das ações preventivas e da crítica à violência do Estado. Nos anos 1980, segundo o artigo, a segurança deveria ser mais punitiva com encarceramento prolongado (e sofrido) e aplicação da pena de morte. Esta última, no entanto, parece ter saído de pauta já há alguns anos após uma certa hegemonia do discurso dos direitos humanos e a percepção de que a pena de morte já é aplicada pelos aparelhos de segurança do Estado. Hoje, o encarceramento e a redução da maioridade penal são as principais bandeiras do punitivismo.

1 A campanha de João Doria (PSDB) à prefeitura de São Paulo, em 2016, enfatizou a figura do gestor em detrimento da do político; e a de Jair Bolsonaro (PSL), em 2018, o apresentou como alguém crítico da "velha política" e admirador do regime militar. 
Em relação aos costumes, o problema colocado nos anos 1980 era a pornografia dos cinemas pornôs e das bancas de revistas que "poluíam" a paisagem urbana. Hoje, muitos dos grandes cinemas da cidade tornaram-se templos pentecostais. Olhando retrospectivamente, as questões de gênero conquistaram muita visibilidade e legitimidade nas três últimas décadas no Brasil. Uma das questões dos dias atuais é como lidar com manifestações de afetos entre casais homossexuais e performances de gênero em espaços públicos.

Entretanto, se esses três assuntos (econômico, moral e securitário) atravessam os contextos atual e dos anos 1980, o que mais chama a atenção ao longo da leitura do artigo de Pierucci é a pouca presença dos evangélicos, que é tratada de forma ainda incipiente, só no final do artigo, e muito inferior ao tratamento dado aos católicos, que atravessam todo o texto. Embora já se soubesse do crescimento demográfico dos evangélicos nos anos 1970 e 1980, eles haviam acabado de iniciar uma investida forte na política oficial na eleição para a Constituinte, em 1986. Apesar do curto tempo de atuação como religião pública, ${ }^{2}$ Pierucci chamou a atenção para esse novo "bloco bem barulhento no Congresso Constituinte" que atua na defesa intransigente da moralidade da "família tradicional".

É que sua penetração [do moralismo] na massa é enormemente facilitada por sua dupla e vantajosa aliança: com a extrema direita da mídia policial e com a extrema direita evangélica, esta igualmente midiática (linhagens estas da extrema direita que também se fazem representar no parlamento) [...]. Este novo espaço sociocultural para a extrema direita, representado por denominações cristãs fundamentalistas, converge no seu anticlericalismo específico com o outro, o anticlericalismo-de-caserna-e-delegacia para acusar a arquidiocese de São Paulo de pactuar com os delinquentes através da política dos direitos humanos. (Pierucci, 1987, p. 42, 44-45, grifo meu).

Em síntese, o efeito final do artigo é de que a constelação das ideias e valores conservadores de direita tem camadas mais profundas e longevas. O conservadorismo antecede e ultrapassa a atuação dos evangélicos como religião pública

2 No sentido dado por Casanova (1994, p. 20), qual seja, aquela que não é apenas visível no espaço publico, mas atua sobre ele e sobre suas regras de funcionamento. 
no Brasil. Tendo o artigo de Pierucci como um registro da conjuntura dos anos 1980, quais as inflexões naquilo que é classificado e autonomeado como "de direita" quando um novo ator público começou se configurar a partir da Constituinte: os evangélicos conservadores?

\section{Situando o (neo)conservadorismo}

Judith Butler (2015), em Quadros de guerra, desenvolveu o argumento, tanto teórico quanto metodológico, segundo o qual os conflitos político-culturais que opõem a moral religiosa à diversidade de gênero ou, mais especificamente, os islâmicos aos gays, devem ser compreendidos a partir dos "enquadramentos" que produzem as polarizações e naturalizam as identidades. Como frames (Goffman, 2006), eles são modos de inteligibilidade. A crítica de Butler é direcionada à normatividade das políticas liberais de reconhecimento em contextos multiculturais por não ser reflexiva com sua própria produção de identidades. ${ }^{3} \mathrm{O}$ enquadramento liberal multicultural estrutura as posições dos atores políticos e sociais, os discursos acusatórios e as justificações políticas, os projetos e as ações, etc.; mas nesse âmbito as pautas LGBTI+ são valorizadas em detrimento de posturas religiosas tradicionais como a de alguns islâmicos. Para Butler, as políticas de reconhecimento não somente reconhecem como também fixam certas identidades em relação de antagonismo a outras identidades, a tal ponto que acabam dificultando possíveis coligações (termos da autora) entre elas. Nisso reside "o não-pensamento em nome da normatividade" (título de um dos capítulos de Quadros de guerra) que, ao reconhecer, projeta posições irredutíveis. ${ }^{4}$

3 Em Coisas ditas, Bourdieu (2004, p. 101) afirma que as burocracias estatais são os grandes classificadores sociais. Sua crítica era que a reinvindicação pode fixar o indivíduo na sua condição de necessitado. Butler faz a mesma advertência às políticas de reconhecimento que reificam as diferenças e as antagonizam.

4 O enquadramento de guerra, para Butler, reduz a diversidade a polos antagônicos de posições políticas, algo que se acentuou com o atentado de 11 de setembro nos Estados Unidos e, de modo geral, com os choques sociais e culturais resultantes da globalização, sobretudo em países europeus ocidentais. Em ambos os casos o efeito mais proeminente tem sido o endurecimento de políticas securitárias. 
Retenho de Butler o seu procedimento metodológico que consiste em dar um passo atrás e identificar as condições de possibilidade de alguns discursos e oposições em detrimento de outros. Isto é, qual foi o enquadramento que estabeleceu que ser islâmico é necessariamente ser contra LGBTI+ e vice-versa, por exemplo? Adotando o mesmo procedimento, quais deslocamentos sofreu a sociedade brasileira na atualidade que tornaram alguns discursos mais legítimos e outros ilegítimos?

Como o campo de forças no Brasil está fraturado e polarizado pelo menos desde as eleições de 2014, os indexadores esquerda e direita reacenderam suas cores e outras séries de oposição emergiram a partir da conjuntura pós-junho de 2013: petistas x tucanos, mortadelas x coxinhas, estatistas x privatistas, verde-amarelo $\mathrm{x}$ vermelho, petistas $\mathrm{x}$ bolsonaristas, morais $\mathrm{x}$ imorais, direitos humanos $\mathrm{x}$ homens direitos, corruptos x não corruptos, político x gestor, católicos tradicionais $\mathrm{x}$ católicos progressistas, evangélicos fundamentalistas $\mathrm{x}$ evangélicos progressistas, entre outras. E, como a oposição transversal a todas elas: petismo $x$ antipetismo. ${ }^{5}$

É a partir desse enquadramento polarizado e instável que problematizo o termo "conservadorismo", sobretudo nos seus usos práticos no debate público. De imediato, identifico três usos. Primeiro, o termo tem sido evocado como categoria política de acusação, que circunscreve um conjunto relativamente variado de discursos, posicionamentos, ações e atores considerados opressivos e pouco afeitos às diferenças e às mudanças na estrutura social. Segundo, como uma categoria de autoidentificação. Por sinal, cada vez mais, tais identificações, sobretudo "de direita", vêm sendo assumidas publicamente sem os constrangimentos do período inicial da redemocratização do país (Pierucci, 1987). O termo "progressista" parece não estar tão negativado como "esquerda", ainda. Por fim, "conservadorismo" tem um estatuto conceitual, sobretudo na filosofia política

5 Essa oposição tem estruturado as preferências eleitorais, o que foi sentido no primeiro turno das eleições de 2018 quando a posição antipetista foi capturada por Bolsonaro, superando a oposição PT x PSDB das seis eleições presidenciais anteriores. No segundo turno, a oposição se estrutura na mútua rejeição entre os candidatos, e se configura como anti-PT x anti-Bolsonaro. Ao fim do pleito, Bolsonaro ganhou o segundo turno com $55 \%$ contra $45 \%$ de Haddad entre os votos válidos. Mas entre os evangélicos, segundo pesquisa do Instituto DataFolha a três dias da eleição, a diferença foi de $69 \%$ a $31 \%$ a favor de Bolsonaro entre votos válidos. Cabe ressaltar ainda que cerca $30 \%$ dos eleitores não votaram em nenhum dos dois candidatos ( $21,3 \%$ de abstenções, $2,14 \%$ de votos brancos e 7,43\% de nulos). 
e na ciência política, que informa e, por vezes, se sobrepõe aos sentidos mais corriqueiros do debate público.

O objetivo deste artigo, no entanto, não é partir de uma definição conceitual para depois aferir a realidade empírica ou, inversamente, utilizá-la como ilustração do conceito. A conceituação interessa mais como ferramenta do que como um indexador de experiências históricas. Assim, apreendo conservadorismo como uma categoria social informada parcialmente pelo debate político e pelo acadêmico. Parcialmente porque os usos do termo como acusação, autoidentificação ou conceito não se sobrepõem com exatidão, mas estão em circulação e, muitas vezes, indiferenciados nas discussões sobre o país na atualidade.

Isso me leva a um artigo de Samuel Huntington, ${ }^{6}$ um dos principais pensadores do conservadorismo norte-americano. Sua formulação corrobora o procedimento metodológico de apreensão do termo em seu uso prático, situado e relacional. Huntington elenca três tradições de entendimento mais frequentes do que ele definiu como "conservadorismo como ideologia". São elas: a identificação histórica com um segmento específico (a aristocracia); a definição autônoma em relação à experiência histórica a partir de algumas propriedades mais constantes; e, por último, a perspectiva situacional, que surge na defesa das instituições estabelecidas e dos valores instituídos. Sua opção é pela terceira: nem identifica conservadorismo com um segmento social específico nem lhe atribui propriedades descontextualizadas. Nem tanto histórica nem tanto abstrata, mas situada e em relação (Huntington, 1957).

Para Huntington, o conservadorismo não se define propriamente por uma ideologia ideacional (entenda-se, um conteúdo substantivo predeterminado, como o liberalismo, a democracia, o socialismo, o fascismo, etc.), mas uma ideologia posicional, cujo sentido é o de resistência a mudanças. ${ }^{7}$ Nesse sentido, como posicional, o conservadorismo deve ser compreendido situacionalmente, quando impelido a reagir e a resistir às mudanças institucionais e sociais.

6 Ideólogo proeminente do pensamento conservador norte-americano, teve repercussão no debate público com o seu livro Clash of civilizations durante o governo de George W. Bush, do Partido Republicano. O argumento o livro era a irredutibilidade entre a democracia ocidental e o ethos político-religioso islâmico.

7 Daí a sua crítica aos neoconservadores norte-americanos de sua época, seja porque não tinham clareza quanto ao que se opunham (secularismo, multiculturalismo, comunismo, etc.), seja porque, tal como Russell Kirk, recuperavam uma noção nostálgica de conservadorismo. 
Mudança só como reforma, não como ruptura. A prudência é a postura necessária. Cabe conservar as instituições burocráticas, o Estado e a Justiça; o que é estendido às instituições sociais como a família, a comunidade religiosa e a ordem nacional. Huntington elabora essa formulação nos EUA do final dos anos 1950, no contexto da Guerra Fria. Para ele, a postura conservadora situada naquela época implicava reafirmar as instituições liberais que teriam construído, segundo ele, a grandeza da sociedade americana do século XX.

Huntington, um liberal conservador, é significativamente oposto a Butler, uma crítica do neoliberalismo e ideóloga das pautas progressistas relativas aos comportamentos sexuais, de gênero e reprodutivos. Entretanto, ambos oferecem procedimentos metodológicos aproximados. A proposição de Huntington é a de compreender o conservadorismo de modo situado e relacional, enquanto a noção de enquadramento de Butler permite dar um passo atrás para, desse modo, compreender as próprias condições de possibilidades da situação e da posição daquilo que tem sido denominado como conservadorismo evangélico no Brasil hoje.

Assim como outros pensadores, Huntington tratou do conservadorismo político, que, em parte, pode contemplar a tradição nacional e, em boa medida, encontra sustentação na religião. ${ }^{8}$ Mas o que vem sendo acusado e autoidentificado como conservadorismo no Brasil refere-se, principalmente, ao plano dos costumes, fortemente propagado pelas religiões cristãs, em especial as evangélicas. A sacralização da família tradicional é, sem dúvida, o signo de um amplo campo moral em questões relativas ao corpo, ao comportamento e aos vínculos primários.

O conservadorismo dos costumes não pretende se limitar aos religiosos, ao universo da congregação weberiana, ${ }^{9}$ mas alcançar a sociedade como um todo,

8 Huntington destaca a religião como uma das seis características do principal fundador do pensamento conservador moderno, Edmund Burke, a saber: que o homem é um animal religioso e a religião está na fundação da sociedade civil, como uma sanção divina que legitima a ordem. O conservadorismo de Burke (2014), produzido como crítica dos desdobramentos do processo revolucionário francês, defendia e justificava a manutenção das instituições britânicas (monarquia e Igreja Anglicana), acompanhando as mudanças no mundo econômico e o nascimento da burguesia. Burke era um liberal na economia e um conservador nas instituições (Huntington, 1957).

9 No sentido de associação voluntária formada por vínculos puramente religiosos, o que em muitos casos implicará no rompimento com "as relações do clã e do matrimônio" (Weber, 1971, p. 377). 
disputando no plano da norma jurídica os conteúdos substantivos da moralidade pública. O diagnóstico de que o processo de secularização deixaria a religião cada vez mais acantonada na vida privada, como formulou Luckmann (1967) em Invisible religion, já não corresponde à realidade pelos menos desde anos 1970. Esse processo foi identificado por Casanova nos anos 1990, quando elaborou o conceito de religião pública para compreender essa nova realidade. ${ }^{10}$ Aquilo que parecia ter sido restringido à esfera privada e individual pelo processo de secularização reconfigurou-se e atua sobre aquilo que se define como público (mais especificamente, as normas públicas, em forma de lei ou dos costumes).

O ator na América Latina analisado por Casanova, a Teologia da Libertação, tratava da realidade do período das ditaduras latino-americanas e o início das redemocratizações: um ativismo político-religioso à esquerda com ênfase na estrutura socioeconômica. Contudo, atualmente no Brasil e América Latina, o que se destaca são setores religiosos à direita com ênfase na moralidade e nos comportamentos. A atuação dos evangélicos no Legislativo envolve, além das questões de interesse geral para o país, os interesses corporativos do segmento e a pautas dos costumes e comportamentos.

A novidade conservadora no Brasil contemporâneo assemelha-se ao que Wendy Brown diagnosticou no neoconservadorismo norte-americano pós-Reagan e que se acentuou na administração Trump: a expansão da esfera pessoal e protegida. Essa esfera é o espaço da liberdade pessoal que está protegida da intervenção do Estado, como o indivíduo e a família. $\mathrm{O}$ argumento principal da expansão é o de que não se trata apenas da proteção da família tradicional contra o avanço da moralidade liberal, mas de que seus valores devem referenciar o ordenamento público e ser a instituição social de suporte de políticas econômicas que diminuem a proteção social (Brown, 2019; Cooper, 2017).

Frente a esse cenário, como a laicidade no Brasil construída tendo o catolicismo como a religião de referência reage a um novo ator, os evangélicos conservadores à direita, que se comporta como religião pública com pretensão reguladora também do secular?

10 Seus exemplos empíricos foram: a Revolução Islâmica no Irã, o movimento Solidariedade na Polônia, o fundamentalismo evangélico norte-americano e a Teologia da Libertação na América Latina. 


\section{Sectarismo de maioria}

Já há alguns anos o problema da secularização passou a ser como: lidar com a atuação das religiões no espaço público; redefinir os parâmetros para circunscrever o secular; e requalificar os limites do que pode ser aceito como religioso, pois quando o pluralismo religioso e seus direitos foram reconhecidos, a disputa em torno da laicidade se exacerbou (Mariano, 2011).

A ação mais significativa da recente conjuntura da relação entre instituições religiosas e Estado foi a assinatura da concordata entre o Governo da República Federativa do Brasil e a Santa Sé, em 2008, durante o governo Lula, que estabelece um acordo relativo ao estatuto jurídico da Igreja Católica no Brasil, ratificado posteriormente pelo decreto $\mathrm{n}^{\circ}$ 7.107/2010 (Brasil, 2010). O documento, entre outras coisas, concede isenção de impostos às instituições católicas, reconhece seu trabalho em educação e preserva vários bens da Igreja como patrimônio da cultura brasileira. Em reação, evangélicos à direita apresentaram o projeto de lei da Câmara (PLC) 160/2009 (Brasil, 2009), que institui a Lei Geral das Religiões, que postulou isonomia em relação ao estatuto jurídico da Igreja Católica no Brasil. O projeto foi arquivado no final daquela legislatura, em 2010, sem ter sido aprovado em plenário. Em março de 2013, contudo, a Comissão de Constituição e Justiça e de Cidadania aprovou a admissibilidade da proposta de emenda constitucional do deputado goiano João Campos (PSDB), presidente da Bancada Evangélica, que inclui entidades religiosas de âmbito nacional entre aquelas que podem propor Ação Direta de Inconstitucionalidade, iniciativa até hoje restrita apenas às entidades políticas e sindicais.

Assim, interessa ao ativismo político desses evangélicos uma laicidade que os equipare ao catolicismo (feriados, espaços públicos, isenções tributárias, simbologia nacional, entre outros) e que favoreça a concorrência religiosa. Dessa forma, se a Igreja Católica pretende manter sua influência nos patamares mais profundos da estruturação do espaço social, das relações societais e dos sistemas de ordenamento jurídico-político, na atual conjuntura de pluralidade, ela se vê obrigada a afirmar sua diferença e apresentar-se como um ator religioso entre outros.

Da mesma forma, a concorrência entre crenças e a incorporação da ideia de livre manifestação de opiniões como um direito individual multiplicaram as 
divergências em relação às práticas que podem ou não ser consideradas aceitáveis por um Estado laico. O pluralismo religioso no país é ambivalente: por um lado, significa maior pluralidade política, por outro, promove uma concorrência que, por vezes, resulta em intolerância contra certas religiões e contra a diversidade de valores e comportamentos (Almeida, 2019). Nas últimas décadas, a principal demonstração de intolerância em nome da liberdade religiosa tem sido a demonização por parcelas do neopentecostalismo das matrizes afro-brasileiras.

Em um artigo referência publicado em 1993 sobre os conflitos religiosos resultantes das práticas neopentecostais, Luiz Eduardo Soares argumentou que a demonização promovida pela Igreja Universal, ao fim e ao cabo, reconhece a veracidade das entidades espirituais da umbanda por meio de uma "equiparação simbólica" que, por consequência, teria implícito um potencial democratizador (Soares, 1993). Contudo, recentemente, Soares (2019) refez seu argumento dos anos 1990 frente à crescente intolerância religiosa neopentecostal contra as religiões afro-brasileiras nos anos seguintes (Almeida, 2009, 2010; Pierucci; Prandi, 1996).

Em suma, pode-se afirmar que a articulação entre o secular e o religioso, tal como ele se constitui no Brasil contemporâneo, deslocou-se de uma concepção de laicidade que tinha como referência o cristianismo católico para uma laicidade orientada pela pluralidade religiosa concorrencial, que, muito embora ainda seja predominantemente cristã, assume cada vez mais um perfil evangélico.

Boa parte da argumentação pró-conservadorismo dos costumes apela para a constatação de que "o Estado é laico, mas a sociedade é religiosa" ou "o Estado é laico, mas não é ateu". E como a sociedade brasileira é majoritariamente de tradição cristã, deve-se tê-la como a referência para o ordenamento jurídico dos comportamentos. $\mathrm{O}$ argumento da maioria cristã tem aparecido recorrentemente nas falas de players políticos para justificar a imposição de freios às pautas progressistas. Desde a campanha de 2018 até os dias atuais, o presidente Jair Bolsonaro por várias vezes declarou que as minorias (gays, feministas, "abortistas", etc.) devem se adaptar à maioria ou, caso contrário, deveriam sair do país. A julgar por suas sinalizações, Bolsonaro não se situa em uma posição pós-secularista, isto é, a que admite e lida com a diversidade de religiões no espaço público (Habermas, 2007; Taylor, 2014). Ao contrário, está alinhado 
às partes majoritárias do pluralismo cristão crescente no país na sua vertente mais conservadora (política e moralmente).

O apelo dos evangélicos conservadores a uma suposta maioria cristã demográfica necessita indexar o conjunto dos católicos. Há afinidades entre evangélicos e católicos sobre diversas pautas; afinal, o conservadorismo é uma estrutura profunda da sociedade brasileira, transversal às religiões, sobretudo as de matriz cristã. No entanto, a forte pressão por mudanças legais e comportamentais no campo dos vínculos familiares, da sexualidade e de gênero não advêm somente de um tradicionalismo resistente ao mundo em mudança, como poderia ser o caso de setores da Igreja Católica. Esse conservadorismo tradicional reativo foi revigorado por uma postura ativa e propositiva de mudança cultural por parte dos evangélicos. Com esse horizonte, não se trata aqui apenas de reivindicar a proteção estatal da moralidade cristã, mas de inscrevê-la no ordenamento legal do país.

A consolidação dos evangélicos no Brasil no final do século XIX e na primeira metade do XX, contudo, deu-se sob o discurso de garantia da liberdade e de proteção para sua condição de minoria religiosa (Pierucci; Prandi, 1996). Com o advento da Proclamação da República, a separação entre Estado e Igreja Católica implicou a proteção ao exercício das práticas das religiões minoritárias. Ao Estado laico cabe proteger a liberdade de culto, por um lado, e ser neutro entre as religiões, por outro. No entanto, se o sentido de liberdade religiosa que emerge com o advento da República era o de proteção da diversidade de religiões e da liberdade de consciência, entre esses atuais atores religiosos ela é entendida como contenção de minorias, sobretudo as relativas às diferenças comportamentais e identitárias. Conforme cresceram demograficamente e atingiram espaços de poder, vetores do evangelismo brasileiro têm sustentado um entendimento da democracia voltado mais para a vontade da maioria do que para a proteção das minorias ou das diferenças.

A distinção entre igreja e seita feita por E. Troeltsch é um bom referente para equacionar esse conservadorismo religioso no Brasil hoje. Igreja é uma instituição coextensiva à ordem social, como se religião e tradição cultural se sobrepusessem: a associação entre ser brasileiro e ser católico, por exemplo (Sanchis, 2018). Seita, por sua vez, tem um movimento contra o status quo religioso (Troeltsch, 1987); e se for ainda salvacionista, ela tem a pretensão de ser a religião da maioria. Contudo, não se trata de tornar-se uma religião coextensiva 
à ordem social, mas, inversamente, o social dever ser coextensivo à religião cristã. Esse tem sido um dos sentidos da ação desses evangélicos à direita no Brasil contemporâneo.

\section{Consideração final}

Não é possível, entretanto, generalizar os evangélicos a partir dessas posições. Quando se intensificou no país o debate público (na verdade, mais restrito às camadas escolarizadas) em torno das pesquisas com células-tronco embrionárias e, a reboque naquele momento, o da legalização do aborto, a Igreja Universal declarou-se a favor das pesquisas ${ }^{11}$ e admitiu o aborto nos casos já definidos pela legislação brasileira (estupro, perigo de vida para a mãe e feto com anencefalia). ${ }^{12}$ Tais posições foram uma forma da Igreja Universal se colocar na discussão em contraposição à Igreja Católica. Mais recentemente, o bispo Macedo tem feito pregações no sentido de que não cabe às igrejas evangélicas atuarem para que o Estado estabeleça proibições em questões consideradas religiosas. O Estado não deve ser instado a tratar desses temas, mais especificamente: o ensino religioso, a homoafetividade, o aborto e as pesquisas com células-tronco embrionárias. Entretanto, os deputados do PRB ligados à Igreja Universal fizeram pouquíssimas proposições na Comissão de Direitos Humanos e Cidadania presidida pelo deputado Marcos Feliciano, mas acompanharam o voto conservador dos outros evangélicos, principalmente da Assembleia de Deus, a mais militante das pautas conservadoras (Gonçalves, 2016).

Em síntese, os evangélicos que têm seguido a trajetória eleitoral não são unívocos nos posicionamentos, mas de forma geral trabalham a favor das pautas moralizadoras. A diferença entre os posicionamentos está no quanto $o$ Estado deve legislar sobre os comportamentos, o que faz da laicidade um valor público assumido discursivamente por todos (papa Francisco, Marina Silva,

11 Além dela, manifestaram-se também a favor setores mais liberais do protestantismo histórico, como a Igreja Metodista e a Igreja Presbiteriana do Brasil.

12 Os dois primeiros casos estão contemplados no art. 128 do Código Penal brasileiro, já o terceiro, na Arguição de Descumprimento de Preceito Fundamental n. 54 do STF, de 2012. 
bispo Macedo, Silas Malafaia, Marcos Feliciano, CNBB, etc.), mas com sentidos variados e em disputa. No que refere aos evangélicos à direita, em termos práticos, o espaço público e a máquina estatal (ações e leis) são campos de atuação para promover, entre outras coisas, a contenção do liberalismo moral e a transformação de costumes e comportamentos.

\section{Referências}

ALMEIDA, R. A Igreja Universal e seus demônios: um estudo etnográfico. São Paulo: Terceiro Nome, 2009.

ALMEIDA, R. Religião em transição. In: DUARTE, L. F. D.; MARTINS, C. B. (coord.). Horizontes das ciências sociais: antropologia. São Paulo: Anpocs, 2010. p. 367-405.

ALMEIDA, R. Religião e laicidade. In: SCHWARCZ, L. M.; STARLING, H. M. Dicionário da República: 51 textos críticos. São Paulo: Companhia das Letras, 2019. p. 299-305.

BOURDIEU, P. A codificação. In: BOURDIEU, P. Coisas ditas. São Paulo: Brasiliense, 2004. p. 96-107.

BRASIL. Senado Federal. Projeto de lei da Câmara n 160, de 2009. (nº 5.598/2009, na Casa de origem, do Deputado George Hilton). Dispõe sobre as Garantias e Direitos Fundamentais ao Livre Exercício da Crença e dos Cultos Religiosos, estabelecidos nos incisos VI, VII e VIII do art. $5^{\circ}$ e no $\$ 1^{\circ}$ do art. 210 da Constituição da República Federativa do Brasil. Brasília, 2009. Disponível em: https://www25.senado.leg.br/ web/atividade/materias/-/materia/92959. Acesso em: 15 set. 2019.

BRASIL. Decreto $n^{\circ} 7.107$, de 11 de fevereiro de 2010. Promulga o Acordo entre o Governo da República Federativa do Brasil e a Santa Sé relativo ao Estatuto Jurídico da Igreja Católica no Brasil, firmado na Cidade do Vaticano, em 13 de novembro de 2008. Brasília, 2010. Disponível em: http://www.planalto.gov.br/ccivil_03/_ato20072010/2010/decreto/d7107.htm. Acesso em: 15 set. 2019.

BROWN, W. Nas ruínas do neoliberalismo: a ascensão da política antidemocrática no Ocidente. São Paulo: Politéia, 2019.

BURKE, E. Reflexões sobre a Revolução na França. São Paulo: Edipro, 2014.

BUTLER, J. Quadros de guerra: quando a vida é passível de luto?. Rio de Janeiro: Civilização Brasileira, 2015. 
CASANOVA, J. Public religions in the modern world. Chicago: The University of Chicago Press, 1994.

COOPER, M. Familyvalues: between neoliberalism and the new social conservatism. New York: Zones Books, 2017.

GOFFMAN, E. Frame analysis: los marcos de la experiencia. Madrid: Centro de Investigaciones Sociológicas, 2006.

GONÇALVES, R. B. O discurso religioso na política e a política no discurso religioso: uma análise da atuação da Frente Parlamentar Evangélica na Câmara dos Deputados (2003-2014). 2016. Tese (Doutorado em Sociologia) - Instituto de Estudos Sociais e Políticos, Universidade do Estado do Rio de Janeiro, Rio de Janeiro, 2016.

HABERMAS, J. Entre naturalismo e religião: estudos filosóficos. Rio de Janeiro: Tempo Brasileiro, 2007.

HUNTINGTON, S. P. Conservatism as an ideology. The American Political Science Review, v. 51, n. 2, p. 454-473, June 1957.

LUCKMANN, T. The invisible religion: the problem of religion in modern society. New York: The Macmillan Company, 1967.

MARIANO, R. Laicidade à brasileira: católicos, pentecostais e laicos em disputa na esfera pública. Civitas: Revista de Ciências Sociais, v. 11, p. 238-258, 2011.

PIERUCCI, A. F. As bases da nova direita. Novos Estudos, São Paulo, n. 19, p. 26-45, dez. 1987.

PIERUCCI, A. F. Ciladas da diferença. In: PIERUCCI, A. F. Ciladas da diferença. 3. ed. São Paulo: Editora 34, 2013. p. 14-57.

PIERUCCI, A. F.; PRANDI, R. (org.). A realidade social das religiões no Brasil. São Paulo: Hucitec, 1996.

SANCHIS, P. A religião dos brasileiros. In: SANCHIS, P. Religião, cultura e identidades: matrizes e matizes. Petrópolis: Vozes, 2018. p. 245-279.

SOARES, L. E. Dimensões democráticas do conflito religioso no Brasil: a guerra dos pentecostais contra o afro-brasileiro. In: SOARES, L. E. Os dois corpos do presidente e outros ensaios. Rio de Janeiro: Relume Dumará, 1993. p. 85-107.

SOARES, L. E. Revoluções no campo religioso. Novos Estudos, São Paulo, v. 38, n. 1, p. 85-107, jan./abr. 2019. 
TAYLOR, C. How to define secularism. In: STEPAN, A.; TAYLOR, C. (ed.). Boundaries of toleration. New York: Columbia University Press, 2014. p. 59-78.

TROELTSCH, E. Igreja e seitas. Religião \& Sociedade, Rio de Janeiro, v. 14, n. 3, p. 134$144,1987$.

WEBER, M. Ensaios de sociologia. Rio de Janeiro: Zahar, 1971.

Recebido: 06/03/2020 Aceito: 04/27/2020 | Received:3/6/2020 Accepted: 4/27/2020 